\title{
Reassess - Realign - Reimagine: A Guide for Mentors Pivoting to Remote Research Mentoring
}

Christine Pfund ${ }^{1,2,7}$, Janet L. Branchaw ${ }^{3}$, Melissa McDaniels ${ }^{2}$, Angela Byars-Winston ${ }^{4}$, Steve Lee $^{5}$, and Bruce Birren ${ }^{6}$

${ }^{1}$ Institute for Clinical and Translational Research, University of Wisconsin-Madison, Madison, WI

${ }^{2}$ Wisconsin Institute for Science Education and Community Engagement and Department of Kinesiology, University of Wisconsin-Madison, Madison, WI

${ }^{3}$ Wisconsin Center for Education Research, University of Wisconsin-Madison, Madison, WI

${ }^{4}$ Department of Medicine and Center for Women's Health Research, University of WisconsinMadison, WI

${ }^{5}$ School of Humanities and Sciences, Stanford University, Stanford, CA

${ }^{6}$ Broad Institute of MIT and Harvard, Cambridge, MA

${ }^{7}$ Corresponding author

Keywords: mentor, mentoring, graduate, advisor, psychosocial 


\section{Abstract}

Maintaining your research team's productivity during the COVID-19 era can be a challenge. Developing new strategies to mentor your research trainees in remote work environments will not only support research productivity, but also help to keep your mentees' academic and research careers on track. We describe a three-step process grounded in reflective practice that research mentors and mentees can use together to reassess, realign and reimagine their mentoring relationships to enhance their effectiveness, both in the current circumstances and for the future. Drawing on evidence-based approaches, a series of questions for mentees around documented mentoring competencies provide structure for remote mentoring plans. Special consideration is given to how these plans must address the psychosocial needs and diverse backgrounds of mentors and mentees in the unique conditions that require remote interactions. 


\section{Introduction}

An unprecedented situation requiring remote research mentorship from faculty and research group leaders has emerged from the COVID-19 health crisis. Within a matter of weeks, active laboratories and research centers were required to close and many universities were forced to suspend nearly all research-related operations to comply with executive orders. Consequently, research productivity has been negatively impacted and tens of thousands of undergraduate, graduate and postdoctoral research mentees have suddenly only been able to engage with their mentors remotely. Even as laboratories and research centers reopen, there are guidelines for social distancing that will extend the impact of the pandemic on research productivity and mentoring relationships.

The ability of mentors to pivot and adopt new ways to lead their research teams during this time will be a critical factor in maintaining research productivity and fostering talent development. In this essay, we apply the metacognitive concept of reflective practice to remote research mentorship and offer strategies to help mentors build positive research mentoring relationships that keep mentee learning and development on track and maintain research productivity in remote working environments.

\section{Conceptual Background}

Following Schon's (1983) original articulation of the reflective practitioner, Eraut (2006) clarified that reflective practice occurs in three distinct time frames: 1) 'in action' while applying one's practice; 2) 'on action' after one's practice takes place; and, 3) 'for action' considering for what purpose(s) one can develop their practice in the future. In any organization, including a research team, leaders need to be nimble and adjust the ways they look at problems, address challenges, and carry out their work, particularly in times of institutional change (Bollman \& Deal, 2013). As research team leaders and mentors navigate changing professional environments, they must be able to reframe their practice (Schon,1983), reimagine actions that were previously routine, and consider how new circumstances demand different ways of working. Reflective practice is vital to providing effective leadership and mentoring in this complex, evolving research environment created by COVID-19.

\section{Remote Research Mentoring: Making the Most of It Through Reflective Practice} Remote mentoring refers to developmental relationships at a distance that can be sustained using synchronous (e.g., telephone, electronic chat, video calling/meetings) or asynchronous (e.g., e-mail, analog mail and shipping options, chat rooms) methods. It can easily be conflated with computer-mediated communication (CMC) or e-mentoring (Bierema \& Merriam, 2002). However, e- mentoring relationships are intentionally designed to take place in device-mediated electronic spaces, while remote mentoring takes advantage of the affordances of asynchronous and synchronous technologies to support a developmental relationship at a distance.

The involuntary, unplanned remote and socially distanced research mentoring that has been forced by the current pandemic requires many research mentors and mentees to quickly pivot to engage with each other in new ways. This is similar to the situation described for Emergency Remote Teaching (Hodges et al., 2019) in which the abrupt change and uncertain duration of a complex, evolving situation can cause physical stress, mental stress, and anxiety, all of which can be further exacerbated by variable access to the technical and professional resources needed to support teaching (or mentoring) in remote work environments.

Working in complex, evolving crisis conditions, with the worries and uncertainties that come with the current pandemic, add to the heightened stress experienced by both mentors and mentees. Consequently, increased attention on psychosocial practices in mentoring relationships that 
facilitate mental, emotional, and physical well-being is needed. "Psychosocial mentoring enhances a mentee's sense of identity, competence, and effectiveness in a professional role" (Kram, 1985) and can take the form of role-modeling, conveying unconditional positive regard and affirmation, attending to mentees' values, and providing emotional support by discussing mentees' concerns and assisting them with problem-solving (National Academies of Science, Engineering and Medicine, 2019). Though these functions often receive comparatively less attention in person and mentors may be uncomfortable or unfamiliar dealing with these issues, it is important that they be considered and addressed during this period of forced, remote mentoring.

Despite the challenges inherent in suddenly shifting to remote mentoring during the health pandemic, the current crisis provides an opportunity to reflect on mentoring approaches and to re-think strategies to improve mentorship. As Rahm Emanuel has said, "Never let a serious crisis go to waste." The incorporation of structures (e.g., online video meetings, shared online documents) and strategies (e.g., more frequent check-ins, explicit goal setting) to support effective remote mentorship may actually achieve more functional in-person mentoring relationships beyond the post-COVID-19 era. As they pivot to remote mentoring, mentors should be reflective practitioners by leveraging the known benefits of remote work, such as increased flexibility in schedules, lack of commute time, and more time with family (State of Remote Work Report, 2020). It has been shown that individuals whose work requires significant problem-solving, like researchers' work, may actually be more effective and more satisfied when working remotely (Golden et al., 2019). Therefore, if well designed, the new structures and strategies that mentors incorporate into their practice to mentor remotely may lead to increased happiness and productivity for some mentees in the long run (Meiners, 2020).

As reflective practitioners, mentors should also leverage the evidence base on effective mentoring, including the empirically-informed mentoring competencies that are known to contribute to quality research mentoring relationships (see National Academies of Science, Engineering and Medicine, 2019 for a review). Specifically, we invite research mentors to use the three-step reflective process outlined here to develop mentoring practices that are responsive to their mentees' needs.

\section{Optimizing Remote Research Mentorship: Reassess - Realign - Reimagine}

Effective mentoring behaviors are critical to the development of research mentees; and core mentoring principles in the fields of science, technology, engineering, mathematics, and medicine have been tested and collated (). The three-step process proposed here overlays the lens of a reflective practitioner on these evidence-based mentoring competencies and provides questions (Table 1) to guide research mentors' professional reflection as they develop remote research mentoring plans in collaboration with their research mentees.

\section{Step 1 - Reassess}

Engage your mentee in a conversation around the questions in Table 1. This is an opportunity to discuss attributes of the mentoring relationship that may not have been previously addressed between the two of you or that need to be revisited in a remote working environment and in the current context.

\section{Step 2 - Realign}

Based on your conversation in Step 1, collaborate with your mentee to articulate shared 
goals for maintaining aspects of the mentoring relationship that are going well and improving those that are not, paying particular attention to each of your needs in the current context.

\section{Step 3 - Reimagine}

Develop a mutually agreed upon plan to achieve these goals in your remote work together.

Schedule regular check in meetings to revisit the plan and make changes if necessary.

Plans that are successful should persist beyond the current crisis.

These steps can be revisited as the mentees' needs evolve. Specific mentoring tools and approaches for each competency (Handelsman et al., 2005; Pfund et al., 2006; Pfund et al., 2014; Pfund et al., 2015) are listed in Table 1; many of the tools are also available in the National Academies Online Guide to the Science of Effective Mentorship (https://www.nap.edu/resource/25568/interactive/).

Table 1: Questions for mentees and mentoring tools and strategies to develop strong remote mentoring relationships

\begin{tabular}{|l|l|l|}
\hline \multicolumn{1}{|c|}{ 1. Reassess } & \multicolumn{1}{|c|}{ 2. Realign } & \multicolumn{1}{c|}{ 3. Reimagine } \\
\hline \multicolumn{2}{|l|}{ Maintaining Effective Communication } \\
\hline $\begin{array}{l}\text { What aspects of our in-person } \\
\text { communication were working } \\
\text { well for you? (What aspects } \\
\text { were not working well?) }\end{array}$ & $\begin{array}{l}\text { What communication } \\
\text { strategies would you like to } \\
\text { continue to use remotely and } \\
\text { what new strategies would you } \\
\text { like to try? }\end{array}$ & $\begin{array}{l}\text { How would you prefer to } \\
\text { communicate remotely? } \\
\bullet\end{array}$ \\
\hline
\end{tabular}

Mentoring Tools \& Strategies: regularly scheduled synchronous online meetings with shared agendas; communication style inventories; practicing active listening when online

\section{Aligning Expectations}

What were your research and professional priorities before moving to remote work? How were you tracking progress on your priorities?

\begin{tabular}{l|l} 
What adjustments should we & How would you like to track \\
consider making to these & progress on your priorities in a \\
priorities as a result of the shift & remote working environment? Are \\
to remote work? Have any & there any online tools we could \\
new needs or realities arisen? & use to facilitate tracking remotely?
\end{tabular}

What adjustments should we to remote work? Have any new needs or realities arisen?
How would you like to track there any online tools we could

ans; scheduled accountability check-ins to reaffirm shared expectations; regular progress reports on remote work

\section{Assessing Understanding}

How did you prefer to ask questions and/or confirm your understanding about research and your training experience before we began to work remotely?
In what ways would you prefer to ask questions and/or confirm your understanding about research and your training experience in the remote environment?
What new tools might we use to ask/answer questions and share perspectives in the remote environment? 
Mentoring Tools \& Strategies: online running documents to share questions and answers; instant messaging tools; a shared commitment to respond to inquiries in a timely fashion

\section{Addressing Equity and Inclusion}

What did I do in person that supported your connections and collaborations with our research group? What helps you feel a sense of belonging with our research group or got in the way of this?
How can I help you to stay connected to me and to the research group in a remote working environment? Do you have any circumstances that may make this challenging?
In what new ways could I facilitate our remote research group interactions to ensure everyone is engaged and feels welcome? What new tools or strategies could we use to stay connected?

Mentoring Tools \& Strategies: regular wellness checks with individual mentees; accommodating individual mentee needs when scheduling online research group meetings; provide opportunities for students to talk about their experiences

\section{Fostering Independence}

To what extent were you comfortable with the degree of independence you had working on your research when we were working in person?
Would you like more or less independence in making and carrying out decisions about your project in the remote work environment?
How can I provide the support and oversight you need to make progress on your research project in a remote working environment?

Mentoring Tools \& Strategies: individual development plans; regular progress reports on remote work; online task management tools

\section{Promoting Professional Development}

How clear were your career goals and the timelines for achieving those goals before we began working remotely? What were you doing in person that supported progress toward these goals?
How has working remotely impacted your career goals, the timeline for achieving them, or your ability to engage in activities to make progress toward them?
What can I and/or our research group do to support your career goals and professional development remotely? Is there anything in particular you are worrying about with respect to your future?

Mentoring Tools \& Strategies: individual development plans; mentoring network maps; provide opportunities to discuss the uncertainties of the current and future job market

Additional resources with URLs:

Mentoring in a Time of Crisis and Uncertainty

Mentoring in crisis does not need to put mentorship in crisis: Realigning expectations

Mentoring during the COVID-19 Pandemic

Lab Work Under Isolation 
For Many Graduate Students, Covid-19 Pandemic Highlights Inequities

Mindful Mentorship

NIH Office of Intramural Training and Education-Wellness Resources

American Psychological Association COVID-19 Information and Resources

Crisis Text Line: Free 24/7 Support (in the United States, Canada, United Kingdom)

\section{Self-care and Caring for Others}

Because crisis conditions can precipitate or exacerbate emotional distress, mentors may also experience personal and professional stressors and anxieties while still needing to support their mentees. Thus, while mentors attend to their mentees' academic and career development, they must also attend to their own wellness. Some questions to consider when tending to their own or their mentees' wellness include: "Do I/you have a positive strategy(-ies) to handle stress?"; "How might I support my/your self-care during this time?"; "Do I/you have at least one practice that brings meaning to my/your day, week, or month?"; "What support resources are available to me/you (e.g., local campus, national)?"

\section{Focusing on What Matters the Most: The Relationship}

What matters most in remote mentoring, as in face-to-face mentoring, is the relationship itself (National Academies of Science, Engineering and Medicine, 2019; Hernandez, Estrada, Woodcock \& Schultz, 2017). Whether working remotely or in person, it is important that mentors prioritize attending to the well-being and humanity of their mentees as they facilitate their research and professional development. Inviting research mentees to share their psychosocial needs when developing remote mentorship plans is particularly important (Eby et al, 2019). If mentors do not invite mentees to share their psychosocial needs and reassure them that these needs are important, mentees may feel uncomfortable sharing the difficulties they are experiencing due to the power dynamics of the relationship, a lack of trust in the relationship, or for fear that their concerns could be interpreted as excuses by their mentor. For example, mentees may be overwhelmed by the volume of electronic communication they are receiving, the lack of structure to guide their work, slower progress through transitions in career stages, financial uncertainty, or too much or too little contact with their families. Without knowledge of the kinds of psychosocial challenges their mentees are facing, mentors may unknowingly develop remote mentorship plans that actually inhibit their mentee's research productivity and development. For example, a mentor could suggest that this is the perfect time for a mentee to take online classes, analyze data and write, while in reality, the mentee is struggling to find a quiet place with consistent internet connectivity, or may have caregiving responsibility for family members or others who are ill or suddenly unemployed.

Understanding a mentee's psychosocial needs is especially important for mentees with whom mentors may not have had a strong connection in person (Blake-Beard et al, 2011). The needs and responses of mentees will vary widely, so actively inviting all mentees to share their psychosocial needs will help ensure that mentors are attuned to their mentees across social and cultural groups, not just those from similar backgrounds, or who are most vocal or self-initiating. Furthermore, active listening by the mentor in conversations with mentees is especially important because their lived experience outside of the lab may be unfamiliar to and different from the challenges they experience. In sum, we encourage mentors to be intentional in 
cultivating the human and empathic parts of their mentoring relationships with all of their mentees (Godian, 2020), which includes not only feeling concern and perspective-taking but a willingness to act in addressing their needs.

\section{Conclusion}

Advancing your research agenda in extreme circumstances like a pandemic requires creativity, flexibility, and regular communication with your research team members, especially those who are in training and rely on your mentorship to guide their learning and development. Be kind, do not make assumptions, ask questions, actively listen to the answers, and offer understanding and flexibility. Take advantage of the opportunity that a remote working environment presents to be a reflective practitioner and to reassess, realign and reimagine your research mentoring relationships. The structures mentors create now to ensure productive interactions with research mentees and their progress on research projects, while regularly acknowledging the importance of psychosocial well-being, is likely to yield lasting benefits, including more effective mentoring relationships with those mentees and higher research productivity in the future.

Acknowledgements: We thank Rick McGee, Pam Asquith, Stephanie House and Sonia Zarate for their insightful feedback on this article. We also thank the following for their support of the authors: The University of Wisconsin-Madison (UW-Madison) Departments of Kinesiology (JB) and Medicine (ABW); the Howard Hughes Medical Institute (GT11808, BB, CP, ABW); the National Institute of Health NHGRI to the Broad Institute (HG006682; BB) and NCATS to the UW-Madison (UL1TR002373-01, CP). 


\section{References}

Bierema, L.L., Merriam, S.B. (2002). E-mentoring: Using Computer Mediated Communication to Enhance the Mentoring Process. Innovative Higher Education 26, 211-227.

Blake-Beard, S., M. L. Bayne, F. J. Crosby, \& C. B. Muller. (2011). Matching by race and gender in mentoring relationships: Keeping our eyes on the prize. Journal of Social Issues 67(3), 622643.

Bollman, L.G., \& Deal, T.E. (2013). Reframing organizations: Artistry, choice, and leadership. San Francisco, CA: Jossey-Bass.

Cameron, K., Daniels, L., Traw, E., \& McGee, R. (2020). Mentoring in crisis does not need to put mentorship in crisis: Realigning expectations. Journal of Clinical and Translational Science, $1-8$.

Chopra \& Saint (2020). Mindful Mentorship. Healthcare 8(1), 100390.

Eby, L. T., Allen, T.D., Hoffman, B.J., Baranik, L.E., Sauer, J.B., Baldwin, S., ...\& Evans, S.C. (2013). An interdisciplinary meta-analysis of the potential antecedents, correlates, and consequences of protégé perceptions of mentoring. Psychological Bulletin 139(2):441-476.

Eraut, M. (1995) Schon shock: A case for refraining reflection- in- action? Teachers and Teaching, 1:1, 9-22.

Godian, R. (2020). Mentoring during the COVID-19 pandemic. Nature Career Column.

Golden, T.D. \& Gajendran, R.S. 2019. Unpacking the Role of a Telecommuter's Job in Their Performance: Examining Job Complexity, Problem Solving, Interdependence, and Social Support. J Bus Psychol 34, 55-69.

Handelsman, J., Pfund, C., Lauffer, S.M., \& Pribbenow, C.M. (2005). Entering mentoring: A seminar to train a new generation of scientists. Madison, WI: University of Wisconsin Press.

Hernandez, P. R., Estrada, M., Woodcock, A., \& Schultz, P. W. (2017). Mentor qualities that matter: The importance of perceived (not demographic) similarity. Journal of experimental education, 85(3), 450-468.

Hodges, C., Moore, S., Lockee, B., Trust, T., \& Bond, A. (2020). The difference between emergency remote teaching and online learning. Educause Review. Retrieved from https://er.educause.edu/articles/2020/3/the-difference-between-emergency-remote-teachingand-online-learning on March 29, 2020.

Kram, K. E. (1985). Mentoring at work: Developmental relationships in organizational life. Glenview, IL: Scott Foresman.

Meiners, J. (2020, February). Why and How You Should Let Your Postdocs Work Remotely. Chronicle of Higher Education. Retrieved from http://chronicle.com

National Academies of Sciences, Engineering, and Medicine (2019). The Science of Effective Mentorship in STEMM. Washington, DC: The National Academies Press. 
Pfund, C., Pribbenow, C.M., Branchaw, J., Lauffer, S.M., \& Handelsman, J. (2006). The Merits of Training Mentors. Science 311(5760):473-474.

Pfund, C., House, S.C., Asquith, P., Fleming, M.F., Buhr, K.A., Burnham, E.L. ...\& Sorkness, C.A. (2014). Training mentors of clinical and translational research scholars: A randomized controlled trial. Academic Medicine 89(5):774-782.

Pfund, C., Branchaw,J.L., \& Handelsman, J. (2015). Entering Mentoring Version 2. New York, NY: W. H. Freeman.

Schon, D.A. (1983). The reflective practitioner: How professionals think in action. Basic Books: New York, NY.

State of Remote Work Report. (2020 April). Retrieved from: https://buffer.com/state-of-remotework-2019\# on April 30, 2020. 